\title{
Bir Endüstriyel Fan Tasarımı ve Hesaplamalı Akışkanlar Dinamiği ile Analizi
}

\author{
Ömer Korcan ATEŞ*, Ramazan SELVER
}

Süleyman Demirel Üniversitesi, Mühendislik Fakültesi, Makina Mühendisliği Bölümü, 32260, ISPARTA,

Geliş / Received:03/09/2019, Kabul / Accepted: 18/03/2020

\section{$\ddot{O} z$}

$\mathrm{Bu}$ çalışmanın amacı, fan tasarımlarında HAD ile doğru analiz parametrelerinin belirlenmesidir. Bunun için, farklı analitik yöntemlerden deney sonuçlarına en yakını bulunarak bir metodoloji seçilmiş ve uygulanmıştır. Bu metodoloji ile, daha önce test edilen bir fanın aynı girdi verileri kullanılarak tasarlanan fan, hem geometrisi hem de performans sonuçları bu test edilmiş fan ile karşılaştırılmıştır.

Daha sonra, önceden test edilmiş fan üzerinde HAD (Hesaplamalı Akışkan Dinamiği,) analizi yapılmıştır. Farklı ă yapılarında zamandan bağımsız çözdürülen analiz sonuçları tablolar halinde sunulmuş, en uygun ve en az kaynak tüketen minimum ağ sayısı tespit edilmiştir. Nümerik analiz sonucu çıkan sonuçlar, test edilmiş fanın deney sonuçları ile karşılaştırılmış ve düşük bir hata yüzdesi ile tutturulmuştur. $\mathrm{Bu}$ da bize, aynı analiz ayarlarında bu sefer yeni tasarlanan fan geometrisine uygulanan HAD yönteminin kabul edilebilir sonuçlar vereceğini kanıtlamıştır. Sonrasında analitik hesaplardan çıkan çizim değerlerine göre modellenen yeni tasarlanan fan aynı ayarlar ile analiz edilmiş ve tasarım esnasındaki kabuller, bu HAD analizinin sonuçlarına göre revize edilerek deneysel katsayı değerleri olan bir K' faktörü bulunmuştur.

Son olarak bu ulaşılan katsayılara göre yenilenen fan, tekrar aynı nümerik hesaplama işlemlerinden geçirilerek yeni sonuçlar çıkarılmıştır. Yeni tasarlanan fanımızın birçok bölgesindeki veriler alınarak analitik hesaplarla karşılaştırılmış ve kabul edilebilir sınırlar içinde olduğu görülmüştür.

Anahtar Kelimeler: Endüstriyel Santrifüj Fan, Hesaplanabilir Akışkanlar Dinamiği (HAD), Tasarım, Solidworks, Ansys CFX

\section{Design and Computable Fluid Dynamics Analysis of an Industrial Fan}

\begin{abstract}
The aim of this thesis is to define the parameters of CFD analysis in a centrifugal fan design. For this purpose a centrifugal fan is designed by a methodology. This methodology was selected and applied from different analytical methods, which was the closest to the experimental results. At the end, both the geometry and performance results of a previously tested fan and designed fan which is designed by using the same input data of this previously tested fan.

Then, the CFD (Computational Fluid Dynamics) analysis for the pre-tested fan was performed. The results obtained from the numerical analysis were compared with the experimental results. Then, the newly designed fan modeled according to the drawing values obtained from the analytical calculations was analyzed with the same settings and the assumptions during the design were revised according to the results of this CFD analysis and an experimental coefficient value, named K', was found.

Finally, the fan which was renewed according to these coefficients was subjected to the same numerical calculations again and new results were obtained. These results from numerical analysis were taken and compared with analytical calculations and found they were within acceptable limits.
\end{abstract}

Keywords: Industrial Centrifugal Fan, Computable Fluid Dynamics (CFD), Ansys CFX, Design. 


\section{Giriş}

Kovatz ve Desmur (Kovatz ve Desmur, 1958) kanallardaki sürtünme kayıplarının viskozitenin bir fonksiyonu olduğunu ve bunun da Reynolds sayısı ile doğru orantılı olduğunu açıklamıştır. Akışkan türbülanslı bir yapıya ulaştığında duvar pürüzlülüğün de kayıplar arasına alınması gerektiğini söylemiştir. Ayrıca çark ve salyangoz arasında dönen akışkan disk sürtünmesinden ve türbülanstan dolayı normal kanal sürtünme kayıplarından yaklaşık \%50 daha fazla sürtünme kaybına maruz kalmaktadır. Salyangozdaki diğer kayıplar da yüzey pürüzlülüğü ve akışkanın duvarlarına yaklaşımından kaynaklandığını ve bununda salyangozun verimini belirlediğini ortaya koymuştur.

Stodola (Stodola, 1945) çarkın dönüşünün kanatlar arasındaki akışa etkisi olan kayma etkisini (slip factor) tanımlayıcı ilk yöntemi geliştirmiştir. Kanat sayıları ile kayma etkisi arasındaki ilişkiyi ortaya koymuştur. Yaptı̆̆ deneylerle bulduğu sonuçları doğrulayabilmiştir. Kayma etkisi ile ilgili diğer çalışmalar Balje (Balje, 1981), Stanitz (Vibhakar, 2012) ve Eck Bruno (Bruno, 1972) tarafından yapılmıştır. Tüm bu araştırmacılara göre kayma etkisinin kaynağı kanatlar arasındaki girdaplardır. Araştırmaları kayma etkisinin sadece kanat geometrisine bağlı olduğunu göstermiş ve belirli fan çeşitlerinde sabit olduğunu ortaya koymuştur.

A. J. Stepanoff (Stepanoff, 1957) hidrolik kayıpların tüm kayıplar içinde en çok paya sahip olduğunu söylemiştir. Hidrolik kayıpların yüzey sürtünmeleri ve girdaplardan kaynaklandığını ve akışkandaki hız vektörü değişimlerinden dolayı yüzey ayrılmalarının da hidrolik kayıplara yol açtığını ortaya koymuştur. Hidrolik kayıplardan başka şok kayıplarının ve difüzör kayıplarının bu ikinci gruba girdiğini söylemiştir.

Austin H. Church (Church, 1947) pompalar ve körüklerin tasarım metodunu ilk derleyenlerden sayılabilir. Pompa veya fanlarda akışın Reynolds sayısının her zaman belli bir kritik rakamın üzerinde çıktığını yani akışın türbülanslı olduğunu; bu yüzden akış ciddi anlamda bir basınç kaybı yaşandığını söylemiştir. Tasarımına sıkıştırılabilirlik etkisini, basınç oranını ve enerji transferini de dahil etmiştir. Ayrıca fanın belli bölümlerinde sıcaklık ve basınç farklarından dolayı akışkanın yoğunluğunun değişkenliğini de hesaba katmıştır. $\mathrm{Bu}$ da hacimsel debi oranlarının sürekli değişmesine yol açtığını ileri sürmüştür. Akışkan geçişlerinin kesitleri belirlenirken bu hacimsel debi değişimi göz önüne almıştır. Toplam oluşturulan düşü formülünde çark içerisindeki türbülanslar ve sürtünmeden dolayı oluşan basınç kaybı için bir "toplam basınç katsayısı", K' tanımlamış ve bunun deneylerle 0,5 ila 0,65 arasinda çıktığını bulmuştur. Daha sonra Eck Bruno (Bruno, 1972), ve Osborne (Osborne, 1977) gibi araştırmacılar Church'ün bu yöntemlerini geliştirici çalışmalar ortaya koymuşlardır.

D. J. Myles (Myles, 1969) kanat ve difüzördeki kayıpların akışkanın çıkış basınçlarına bağlı olduğunu vurgulamıştır. $\mathrm{Bu}$ kayıpları bir genişleme faktörüne 
bağlamıştır. Düşük debili akışları ayrıca incelemiştir.

Eck Bruno (Bruno, 1972) çark sürtünmesi veya disk sürtünmesi kayıplarını ilk deneysel olarak inceleyen kişidir. Bu kayıpları, çark giriş kayıpları ve çark içindeki sürtünmeler olarak ikiye ayırarak kategorilendirmiştir. Çark içindeki sürtünmeler de akışta gecikme ve basınç kaybı olarak sonuçlandırmıştır. Kanat sayılarının enerji transferine etkisini açıklayan Bruno, optimum kanat sayısını veren bir formül de çıkartmıştır.

Balje (Balje, 1981), santrifüj fanlarda optimum verimin biraz geriye eğimli çarklarla elde edilebildiğini ispatlamıştır. Ayrica kayma etkisi (slip factor) konusunda da literatüre girmiş önemli tespitleri ortaya koymuştur.

William C. Osborne (Osborne, 1977) fanin tasarım noktasındaki ası performansının, ideal fan gücünden farklı olduğunu ve bunun Euler denklemleri ile hesaplanabileceğini söylemiştir. $\mathrm{Bu}$ farkın sebebi kanatların iç yüzeylerindeki girdaplardan kaynaklanmakta ve çarkın yaptı̆̆ olmaktadır. Bunun dışında iç kaçaklar, basınç kayıları ve mekanik kayıplar da fanın yapacağ 1 iş için gerekli gücü arttıran faktörler olduğunu ortaya koymuştur.

Banies ve Whitfield (Whitfield ve Banies, 1990) bir akışkan bölgesinin davranışını tahmin edebilmek için süreklilik, momentum ve enerji denklemlerini tüm akış ortamında kısmi diferansiyel denklemler oluşturmak gerektiğini belirtmişlerdir. Böylelikle turbo makinelerinin içerisindeki akışları nümerik olarak analiz etmişlerdir.
J. D. Denton (Denton, 1993) fan kayb1 "Bir turbo makinenin verimini düşüren tüm akış olayları" olarak tanımlamıştır. Bunun yanında kayıpları "profil kaybı", "ikincil kayıp" (duvar sonu kaybı) ve "sızıntı kayıpları" gibi bölümlere ayırmıştır.

P. J. Roache (Roache, 1997) Hesaplamalı Akışkanlar Dinamiği belirsizliklerini ölçmüştür. Hesaplanabilir Akışkanlar Dinamiği (HAD) işlemini doğrulama, onaylama ve tasdik yöntemleri ile hata tespiti, tahmini ve yakınsama oranlarını ortaya koymuştur.

Frank P. Bleier (Bleier, 1998) hangi tasarım yöntemi kullanılırsa kullanılsın, gerçek fan eğrisi bilgilerine ulaşmak için standart testlerin uygulanması gerektiğgini öne çıkarmıştır. İmalat sanayinde de birçok firma ile çalışan araştırmacı tasarlanan prototipin test sonuçları alındıktan sonra fan yasaları ile ihtiyaca göre dönüştürülüp bir ürün gamı oluşturmayı tavsiye etmiştir. $\mathrm{Bu}$ tez çalışmasında kullanılacak Chicago Blower firması ürünü olan fan da bu yöntemlerle oluşturulmuştur.

Hsin-HuaTsuei, Kerry Oliphant ve David Japikse (Tsuei vd., 1999) turbo makineler için hızlı Hesaplanabilir Akışkanlar Dinamiği (HAD) modelleme yöntemlerini geliştirmişlerdir. $\mathrm{Bu}$ sayede mühendislere Hesaplanabilir Akışkanlar Dinamiği (HAD) materyallerini daha verimli ve etkin kullanma fursatı vermiş olmakla beraber günümüzdeki gelişmiş tasarım tekniklerinin önünü açmışlardır.

Vibhakar (Vibhakar, 2012) ise Church (Church, 1947), Eck Bruno (Bruno, 1972) ve 
Osborne (Osborne, 1977) 'un fan tasarım yöntemlerini uygulayarak, araştırmacıların her bir tasarım adımlarını, bulunan değerlerle kıyaslamış, ayrıca hazırladığı prototipleri deneylerle test ederek, çıkan sonuçları yine her araştırmacının tasarım yöntemi ile karşılaştırmıştır. Bunlar arasında Church'ün yönteminin deney sonuçlarına en yakın olduğunu göstermiştir. Son olarak da HAD sonuçlarını kullanarak deneylerle görülemeyen verilere ulaşmıştır.

Yukarıdaki çalışmalar incelendikten sonra görülmüştür ki, verimli bir fan tasarımında kayma etkisi (slip factor), çark kayıpları, salyangoz kayıpları gibi kayıplar büyük önem taşımaktadır. Bunların hesaplanması ve tahmininde birçok araştırmacının ulaştığ sonuçlar ne yazık ki yeterli oranda birbirlerini ve deney sonuçlarını tutmamaktadır. $\mathrm{Bu}$ durum da bizi, tasarım yaptıktan sonra bir deney düzeneği ile test etmeye mecbur bırakmaktadır. Her tasarlanan fanın test edilerek revize edilmesi ise tahmin edileceği gibi altından kalkılamaz maliyetlerle karşılaşma sonucunu doğurmaktadır. Gelişen bilgisayar teknolojileri ve yazılımlar sayesinde HAD (Hesaplanabilir Akışkanlar Dinamiği) yöntemi, neredeyse deney düzeneklerinin yerini almaya başlamış ve bu çalışmada da yalnızca deneyle tespit edilebilen ve çark kayıplarını temsil eden $K^{\prime}$ faktörü tespit edilebilmiştir. Bunların da ötesinde deney sırasında kullanılan ölçme aparatları ile ölçülemeyecek yerlerdeki değerlere de HAD ile ulaşılabilmektedir.

$\mathrm{Bu}$ makalede, uluslararası profesyonel bir firmanın ürettiği fan (CBC fanı) örnek seçilmiştir. Bu fanın tasarım değerleri (statik basınç, debi, akışkan tipi ve sıcaklığı vb.) kullanılarak yeni bir fan tasarlanmış ve hem çark hem de gövde geometrileri karşılaştırılmıştır. Farkların çok az olması durumunda, sonraki fan hesaplarında bu tasarım yöntemi HAD sonucu $\mathrm{K}^{\prime}$ faktörü tespit edilerek yüksek verimlilikle kullanılabilecektir.

Tasarım girdileri olarak bu fanın ( $\mathrm{CBC}$ fanı) seçilmesinin sebebi, bu fanın deney sonuçlarına göre karakteristik eğrisinin çıkarılmış olmasıdır. Yani tasarım girdilerinin sonuçları deneylerle sağlanmış olduğu için kendini kanıtlamış bir fandır. $\mathrm{Bu}$ fanın HAD sonucu ile Church'ün hesap yöntemi ile tasarlanan fanın HAD sonucu karşılaştırılıp tasarım güncellenerek ideal hesaplama yöntemine ulaşılmıştır.

Tasarlanan fanın her revizyonu sonucunda test etme zorunluluğu sorununu aşmak için HAD yöntemi kullanılarak, bunun sonuçlarının test edilmiş bir fanda sağlaması yapılmıştır. Zamandan bağımsız (steady state) olarak yapılan analizde sınır koşulları olarak girişte $5,24 \mathrm{~kg} / \mathrm{s}$ kütlesel debi, çıkışta atmosfer basıncı ve çark için de $2970 \mathrm{~d} / \mathrm{d}$ lık bir dönüş girilmiş, geometriler $1.050 .771 \mathrm{ağ}$ eleman sayıs1, 366.216 ağ düğüm sayısı ve ortalama 0,278 "skewness" değeri ile işlenmiş ve türbülans modeli olarak da komega/SST seçilerek test edilen fanın oluşturduğu statik basınç \% 5 lik bir hata payı ile tutturulmuştur. $\mathrm{Bu}$ sayede kendini kanıtlayan HAD yöntemi ayarları ile yeni tasarladığımız fanın farklı parametrelerde nasıl sonuçlar verdiği incelenmiş, Church'ün analitik ve sayısal olarak çözmüş olduğu tüm parametreler kavramlar ve sayısal değerler, yapmış olduğumuz tasarım içerisine 
konularak çözdürülmüştür. Sonuç olarak çıkan statik basınç değerlerine göre tasarım yöntemindeki çarkın dönmesinden dolayı oluşan kayma etkisini (slip factor) temsil eden $\mathrm{K}^{\prime}$ katsayısı ortalama değeri olan 0,60 dan 0,57 ye güncellenmiş ve tekrar yapılan analizde hedeflenen $\% 4$ hata payına ulaşılmıştır.

\section{Fan Tasarımı}

Vİbhakar'ın (Vibhakar, 2012) deney cnnuçlarına en yakın değerleri verdiği için l tasarıminda Austin Church'ün (Church,

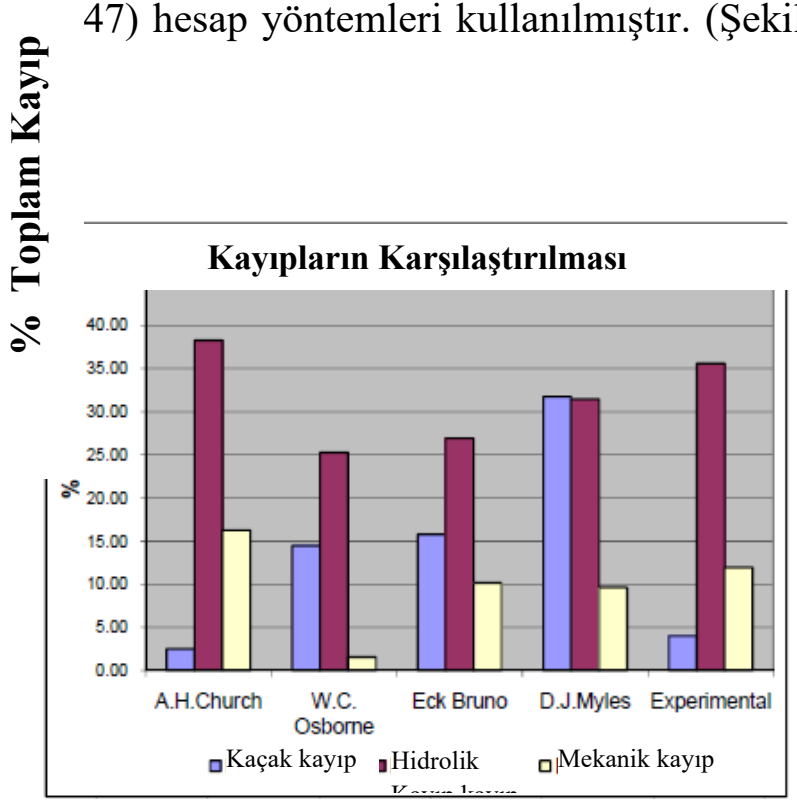

Şekil 1. Farklı tasarım yöntemlerindeki kayıpların deney sonuçları ile karşılaştırılması (Vibhakar, 2012)

CBC fanının müşteri tarafından talep edilen değerleri ve aynı zamanda tasarlanacak fanın girdileri aşağıdaki gibidir;

Çıkış Hacimsel Debisi Q = 5,14 m³/s

Statik Emme Basınc1 $=\mathrm{P}_{\text {emiş }}=-13435 \mathrm{~Pa}$
Statik Basma Basınc1 $=\mathrm{P}_{\text {basma }}=0 \mathrm{~Pa}$

Çark Dönüş Hızı = 2970 d/d

Akışkan (hava) Yoğunluğu= 1,02 Kg/m

Kanat Sayıs $1=10$

Kanat Çıkış Açısı $=56,59$ o

Giriş Sıcaklığ $1=25 \mathrm{C}$ 。

Church'ün (Church, 1947) metodundaki formüller ve fanın girdi ve değerleri kullanılarak çıkarılan rakamlar, bir "Excel" çalışma sayfasına eklenmiştir. Daha sonra kayıpların toplam değeri tasarım basıncına eklenerek yeni iterasyon değerleri bulunmuştur. Aynı şekilde diğer değişkenler de bir sonraki iterasyona yansitılarak aradaki fark $\% 1$ in altına inene kadar iterasyona devam edilmiştir. Sonuç olarak çıkan değerler istenilen tasarım değerlerimiz olmuştur.

Tasarlanan fan, Chicago Blower Coorporation (CBC) firmasinin AMCA standartlarına göre test edilmiş ve oluşturulmuş ürün gamından seçilmiştir ve yurtdışında (Litvanya) bir un fabrikasında kullanılmak üzere imal edilmiştir. Halen sorunsuz çalışmaya devam etmektedir.

Tasarım girdileri olarak bu fanın seçilmesinin sebebi, bu fanın deney sonuçlarına göre karakteristik eğrisinin çıkarılmış olmasıdır. Yani tasarım girdilerinin sonuçları deneylerle sağlanmış olduğu için kendini kanıtlamış bir fandır. $\mathrm{Bu}$ fanın HAD sonucu ile Church'ün hesap yöntemi ile tasarlanan fanın HAD sonucu karşılaştırılıp tasarım güncellenerek ideal hesaplama yöntemine ulaşılmıştır. 
Sağlıklı bir karşılaştırma yapabilmek için, buradaki tasarım yönteminin de bize izin verdiği bazı kabuller yapılmıştır. Bunlar

1. Kanat çıkış açısı $\beta_{2}(56,59$ o)

2. Akışkanın çarka giriş hızı $\mathrm{V}$ giriş $(31,6 \mathrm{~m} / \mathrm{s})$.

Hesaplamalar sonucu çıkan çark değerleri Çizelge 1 de verilmiştir.

Çizelge 1. Tasarlanan Church fanı çark çizim çizelgesi

\begin{tabular}{|l|l|l|l|}
\hline & SEMBOL & BÍRİM & \\
\hline Kanat Çıkış Açısı & $\beta_{2}$ & $\circ$ & 56,59 \\
\hline Kanat Giriş Açısı & $\beta_{1}$ & $\circ$ & 25,63 \\
\hline Giriş Çapı & $\mathrm{D}_{\text {giriş }}$ & $\mathrm{mm}$ & 461,9 \\
\hline Kanat Giriş Çapı & $\mathrm{D}_{1}$ & $\mathrm{~mm}$ & 460 \\
\hline Kanat Çıkış Çapı & $\mathrm{D}_{2}$ & $\mathrm{~mm}$ & 926,5 \\
\hline Kanat Giriş Yüksekliği & $\mathrm{b}_{1}$ & $\mathrm{~mm}$ & 117,2 \\
\hline Kanat Çıkış Yüksekliği & $\mathrm{b}_{2}$ & $\mathrm{~mm}$ & 61,8 \\
\hline
\end{tabular}

Çizelge 1'e göre çizilen çarkın teknik resmi ise Şekil 2 de verilmiştir.

\section{Tasarlanan Fanın Test Edilmiş Fan ile Karşılaștırılması}

\section{1 Çark karşılaştırılması}

Test edilmiş fan (CBC Fanı) çarkının teknik çizimi çarkı Şekil de verilmiştir.

Church yöntemi ile tasarlanan Şekil deki çark değerleri ile CBC'nın tasarımı olan Şekil deki çark değerleri karşılaştırması

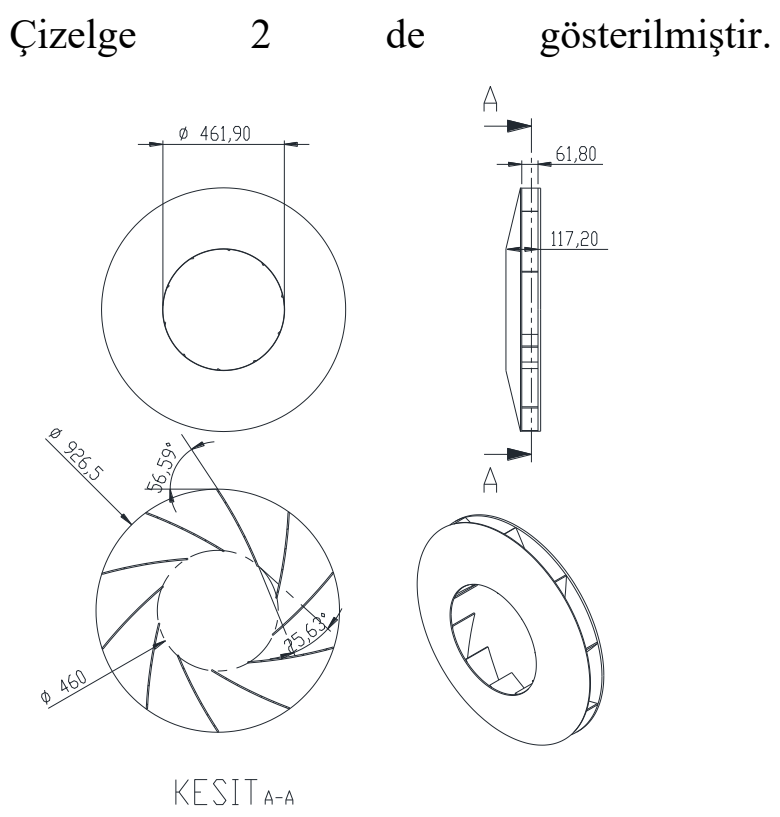

Şekil 2. Church yöntemi ile tasarlanan çark çizimi
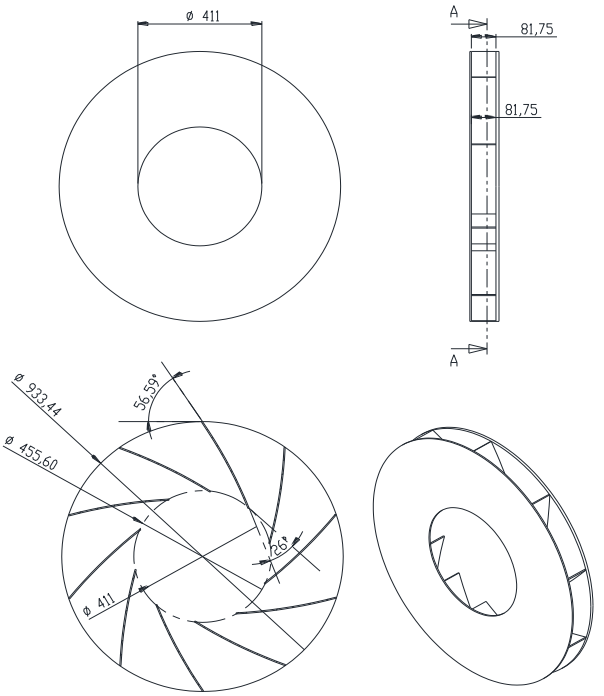

KESIT A-A

Şekil 3. Test edilmiş fanın (CBC fanı) çark çizimi 
Çizelge 2. Church ve CBC çark karşılaştırma çizelgesi

\begin{tabular}{|l|l|l|l|}
\hline & SEMBOL & CHURCH & CBC \\
\hline Kanat Çıkış Açısı & $\beta_{2}$ & 56,59 & 56,59 \\
\hline Kanat Giriş Açısı & $\beta_{1}$ & 25,63 & 26,0 \\
\hline Giriş Çapı & $\mathrm{D}_{\text {giriş }}$ & 461,9 & 411,0 \\
\hline Kanat Giriş Çapı & $\mathrm{D}_{1}$ & 460,0 & 455,6 \\
\hline Kanat Çıkış Çapı & $\mathrm{D}_{2}$ & 926,5 & 933,4 \\
\hline $\begin{array}{l}\text { Kanat Giriş } \\
\text { Yüksekliği }\end{array}$ & $\mathrm{b}_{1}$ & 117,2 & 81,75 \\
\hline $\begin{array}{l}\text { Kanat Çıkış } \\
\text { Yüksekliği }\end{array}$ & $\mathrm{b}_{2}$ & 61,8 & 81,75 \\
\hline
\end{tabular}

\subsection{Salyangoz karşılaştırması}

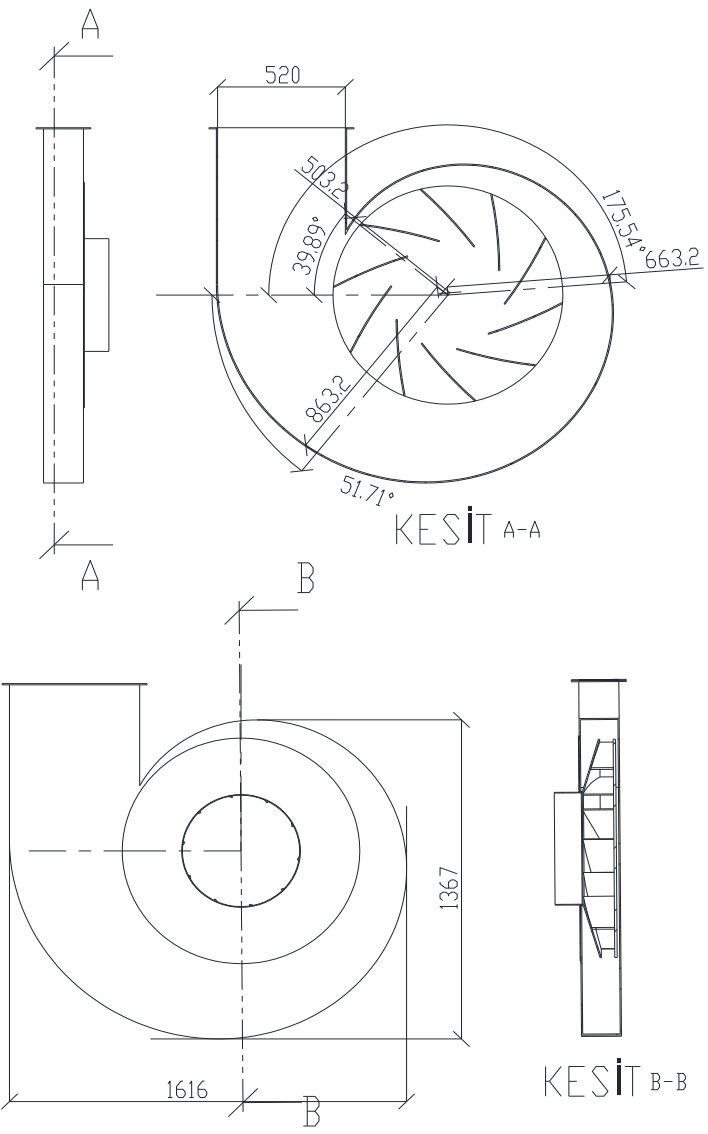

Şekil 4. Tasarlanmış fanın (Church yöntemi) salyangoz çizimi
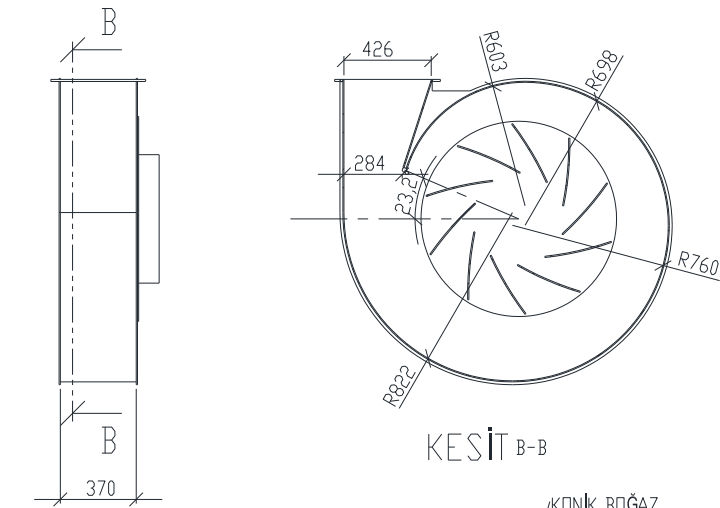

KESIT B-B

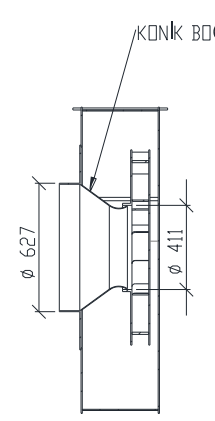

KESIT c-

Şekil 3. Test edilmiş fanın (CBC fanı) salyangoz çizimi

Fanların gövde tasarım farklarının daha iyi anlaşılması için, çark çaplarını da içeren farklı renkle ve çizgilerle karşılaştırılması ise Şekil 6 da gösterilmiştir.
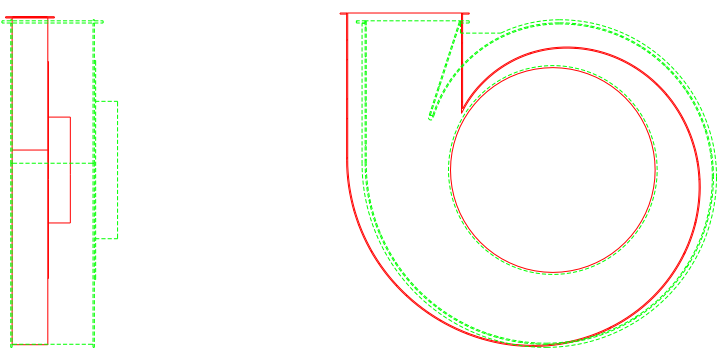

Şekil 6. Tasarlanan ve test edilmiş fanların salyangozlarının karşılaştırması (KırmızıDüz Çizgi: Tasarlanan, Yeşil-Kesikli Çizgi: Test edilmiş ) 


\section{Tasarımların}

Hesaplanabilir

Akışkanlar Dinamiği ile Hesaplanması

$\mathrm{Bu}$ bölümde önce test edilmiş CBC Fanı'nın geometrisi HAD ile çözümlenmiş ve sonuçları çizelgeler halinde sunulmuştur. Daha sonra aynı ayarlarla, Church yöntemi ile tasarlanan fan geometrisinin HAD ile analizi yapılmış ve sonuçları kaydedilmiştir. Çıkan sonuçlara göre tasarım yöntemindeki bazı katsayılar güncellenmiştir.

\subsection{Test edilmiş fanın HAD hesabı}

Modelimizi yükledikten sonra ă̆ (mesh) işlemlerine geçeriz. İşlem sonrası ağın kalitesinin ölçülmesi için farklı yöntemler kullanılmaktadır. Bunlardan en yaygın kullanılanı ise "skewness" değeridir. Kelime anlamı çarpıklık olan "skewness" eşkenar veya eşaçılı mükemmel yüzey veya hücreye yakınlık olarak tanımlanabilir (ANSYS Inc., 2009). Yani "skewness" ne kadar düşükse, mükemmel geometriye o kadar yakınız demektir. (Şekil 7)

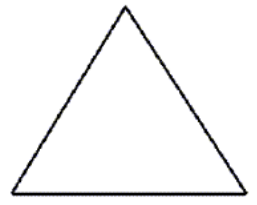

Eskenar Ücgen

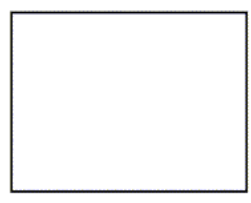

Eşaçılı Dörtgen

(a) İdeal

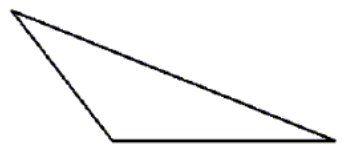

Çarpık Üçgen

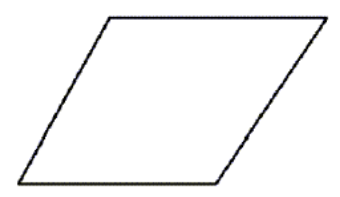

Çarpık Dörtgen

(b) Çarpık
Şekil 7. İdeal ve çarpık geometriler

"Skewness" 0 ile 1 değeri arasında değişir ve bu aralıktaki rakamların anlamları Çizelge 3 de verilmiştir.

Çizelge 3. "Skewness" değeri kalite karș1lkları (ANSYS Inc., 2009)

\begin{tabular}{|l|l|}
\hline "Skewness" & \multicolumn{1}{|c|}{ Hücre Kalitesi } \\
\hline 1 & Çok kötü \\
\hline $0,9-<1$ & Kötü \\
\hline $0,75-0,9$ & Zayıf \\
\hline $0,5-0,75$ & Orta \\
\hline $0,25-0,5$ & İyi \\
\hline$<0-0,25$ & Çok iyi \\
\hline 0 & Eşkenar veya \\
\hline
\end{tabular}

Optimum ağ yapısına ulaşmak için düşük kaliteli ve az sayıda eleman sayısı ile hesaplamalara başlanmış ve sonuçların fazla değişmediği ağ durumu tespit edilene kadar analizlere devam edilmiştir. Buna göre ilk önce toplam 782.821 adet ağ eleman sayıs1 ve ortalama 0,295 Skewness değeri denenmiştir. Daha sonra Çizelge 6.2 de gösterilen değerlerdeki 4 farklı grid sayılarında ağ yapıları çözdürülmüştür.

Çizelge 4. Test edilmiş fanın (CBC fanı) ăg yapısı özellikleri

\begin{tabular}{|c|c|c|c|c|}
\hline 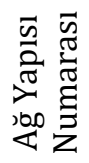 & 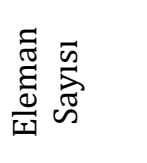 & 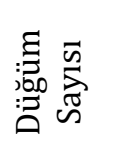 & 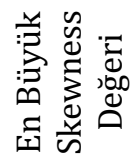 & 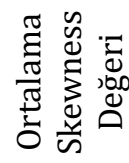 \\
\hline 1 & 782.821 & 237.812 & 0,972 & 0,295 \\
\hline 2 & 856.572 & 252.736 & 0,967 & 0,270 \\
\hline 3 & 1.050 .77 & 366.216 & 0,969 & 0,278 \\
\hline 4 & 1.357 .21 & 441.538 & 0,933 & 0,255 \\
\hline
\end{tabular}

A ̆ yapım işleminden sonra ayarlar (setup) kısmına geçilir. Burada yapılacak simülasyon 
işleminde kullanılacak türbülans modelinden akışkan tipine ve sınır koşullarına kadar tüm girdiler girilir.

Ansys CFX Sonlu Hacimler Yöntemini ve eşitlik olarak da Reynolds-averaged NavierStokes (RANS) eşitliklerini türbülanslı akış1 en iyi hesaplayan model olan "komega/Shear Stres Transport (SST) türbülans modelini (ANSYS,Inc., 2006) ve akışkan olarak da atmosfer basincinda ve $25 \mathrm{C}^{\circ}$ de mükemmel gaz (ideal gaz) seçilmiştir. Türbülans modelini ve akışkan modelini Siwek, Gorski, Stanislaw (Siwek vd., 2014) da araştırmalarında aynı şekilde kullanmış ve başarılı sonuçlar elde etmişlerdir.

Sınır koşulları için girişte kütlesel debi 5,24 $\mathrm{kg} / \mathrm{sn}$, çıkş̧ta ise atmosfer basınc1 olan 101.325 Pa tanımlanmıştır. Ayrıca diğer tüm ortamlar durağanken (stationary), çarka 2970 $\mathrm{d} / \mathrm{d} \quad$ lik bir dönme hareketi (rotation) uygulanmıştır.

Analiz çeşidi zamandan bağımsız (steady) olarak çözülmüştür. Ayrıca çözüm kısmında yakınsamanın tespiti ve sonuçları bilgisayar hesap yaparken görebilmek için kullanıcı tanımlı izlemler (user defined monitors) oluşturulur. Burada giriș ve çıkıșta ortalama statik basınçları ve fanın oluşturacağ 1 statik basıncı görmek için de bunların farkı tanımlanmıştır.

Tüm modelin Ansys'e tanıtılması, ağ yapısı oluşturulması ve ayar basamakları bitirildiğinde son olarak sıra çözüme gelir. Çözüm 17-3630QM @ 2.40 GHz işlemcili ve 32 GB lik bir bilgisayarda kullanılarak ve çekirdek sayısı da 4 olarak ayarlanarak başlatılmıştır. Giriş statik basıncı ve çıkış statik basınc fark1, artan iterasyonlarla $\% 0,5$ den fazla değişmemeye başladığında, yani yakınsadığında işlem durdurulmuştur.

Daha önce tanımlanan giriş ve çıkış yüzeylerinin aritmetik ortalaması olan statik basınç değerleri ve sonuçlarının ağ yapısı numarasına göre sıralaması Çizelge 5 de verilmiştir.

Çizelge 5. Ağ yapısına göre çıkan zamandan bağımsız sonuçlar

\begin{tabular}{|c|c|c|c|c|}
\hline 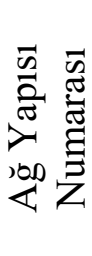 & 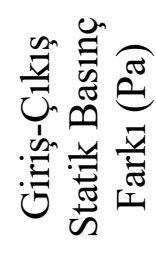 & 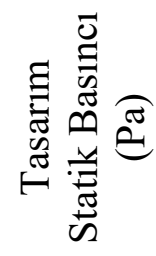 & 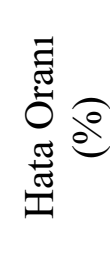 & 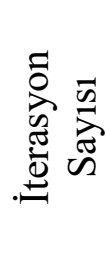 \\
\hline 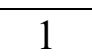 & 12.441 & 13.435 & 7,39 & 139 \\
\hline 2 & 12.6 & 13.435 & 5,55 & 10 \\
\hline 7 & 12. & 13. & 5,11 & 102 \\
\hline 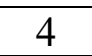 & 12.697 & 13.435 & 5,49 & 157 \\
\hline
\end{tabular}

3 numaralı ağ yapısından sonra sonuçların fazla değiş̧mediği görülmüş ve daha ince bir ağ yapısına bilgisayar kaynaklarının verimli kullanılması açısından gerekli olmadığına karar verilmiştir. Çizelge 5 den anlaşıldığı gibi geçerli HAD ayarlarında fanın oluşturduğu statik basınç \%5 lik bir hassasiyetle tutturulmuştur.

Artık HAD ayarlarının kalibrasyonu yapıldığına göre aynı parametrelerde Church tasarım yöntemi ile (Church, 1947) yeni tasarlanan Church fan geometrisi için de analiz başlatılabilir. 


\subsection{Tasarlanan fanın HAD hesabı}

Tasarlanan fanın ağ yapısının rakamsal değerleri Çizelge 6 da gösterilmiştir.

Çizelge 5 daki 3 numaralı ağ yapısı değerleri ile, Çizelge 6 daki rakamlar incelendiğinde görülmektedir ki Church fanının geometri hacmi $\mathrm{CBC}$ fanından küçük olduğu için eleman ve düğüm sayısı daha azdır, ancak ortalama "skewness" değeri biraz daha düşük, yani bir miktar daha kalitelidir.

Çizelge 4. Tasarlanan fanın (Church fanı) ağ yapısı değerleri

\begin{tabular}{|c|c|c|c|}
\hline 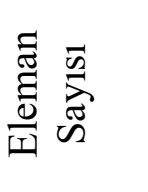 & 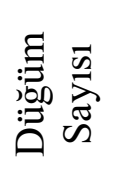 & 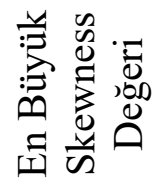 & 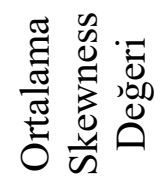 \\
\hline 228.877 & 63.483 & 0,998 & 0,248 \\
\hline
\end{tabular}

Önceki sınır koşulları ve çizim metotları kullanılarak ve aynı bilgisayarla hesaplamalar tekrarlanmıștır.

Fanın giriş ve çıkış yüzeylerindeki statik basınç farkları değerinin yakınsaması sonunda durdurulan analizin sonuçları Çizelge 7 deki gibi çıkmıştır.

Çizelge 7. Tasarlanan fanın (Church fanı) analiz sonuçları

\begin{tabular}{|c|c|c|c|}
\hline 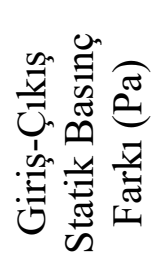 & 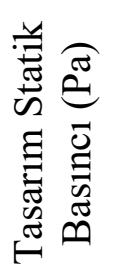 & 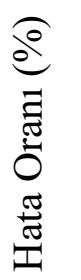 & 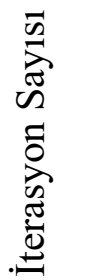 \\
\hline 12.011 & 13.435 & 11 & 1080 \\
\hline
\end{tabular}

Church fanı değerlerini $\mathrm{CBC}$ de çıkanlarla karşılaştırmak için Çizelge 8 aşağıda verilmiştir.

Çizelge 8. $\mathrm{CBC}$ ve Church fanları HAD sonuçları karșılaştırması

\begin{tabular}{|c|c|c|c|c|}
\hline & 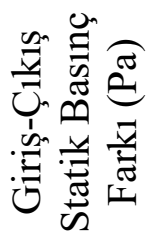 & 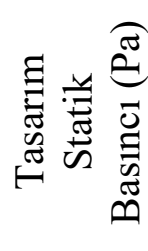 & 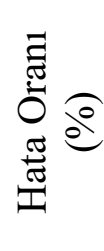 & 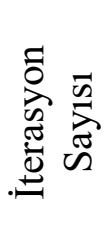 \\
\hline Chur & 12.011 & 13.435 & 11 & 1080 \\
\hline $\mathrm{CBC}$ & 12.741 & 13.435 & 5 & 1026 \\
\hline
\end{tabular}

Çizelge 8 den de anlaşılacağı gibi analiz sonucu CBC fanı değerlerindeki hata oranını yakalayamamıştır. $\mathrm{CBC}$ fanında $\% 5$ ile tutturulan statik basınç fakı, burada \% 11 çıkmıştır. Bu da, tasarım değerlerindeki bazı varsayımlarımızı gözden geçirmemiz gerektiğini göstermektedir.

Church tasarımında, tasarım sonuçlarını etkileyen en büyük varsayım çark içerisindeki türbülans ve sürtünmeleri hesaba katmak için kullanılan $\mathrm{K}$ ' katsayısının tahminidir. $\mathrm{Bu}$ değer tamamen fan tipine bağlı olduğu gibi yapılan deneyler sonucu belirlenebilen bir katsayıdır. Church'ün deney tecrübelerine göre bu değer 5 ile 6,5 arasındadır (Church, 1947). İlk adımda bizim kabul ettiğimiz $\mathrm{K}$ ' değeri 0,60 iken, HAD analizi sonucunda bu kabul istenilen basıncı vermediği için tekrar güncelleyerek 0,57 değeri için hesaplamalar tekrar yapılır. Tasarım eşitlikleri tekrar uygulanılarak yeni bir geometri oluşturulmuştur. Yenilenen son tasarımın çark değerleri Çizelge 9 da verilmiştir. 
Çizelge 9. Yenilenen ve eski $\mathrm{K}^{\prime}$ için Church fanı çark değerleri

\begin{tabular}{|l|c|c|c|c|}
\hline & & & & \\
\hline $\begin{array}{l}\text { Kanat Çıkış } \\
\text { Açısı }\end{array}$ & $\beta_{2}$ & $\circ$ & 56,59 & 56,59 \\
\hline $\begin{array}{l}\text { Kanat Giriş } \\
\text { Açısı }\end{array}$ & $\beta_{1}$ & $\circ$ & 25,63 & 25,63 \\
\hline $\begin{array}{l}\text { Giriş Çap1 } \\
\text { Kanat Giriş } \\
\text { Çapı }\end{array}$ & $\mathrm{D}_{\text {giriş }}$ & $\mathrm{mm}$ & 461,9 & 461,9 \\
\hline $\begin{array}{l}\text { Kanat Çık1ş } \\
\text { Çap1 }\end{array}$ & $\mathrm{D}_{2}$ & $\mathrm{~mm}$ & 460,0 & 460,0 \\
\hline $\begin{array}{l}\text { Kanat Giriş } \\
\text { Yüksekliği }\end{array}$ & $\mathrm{b}_{1}$ & $\mathrm{~mm}$ & 117,2 & 111,2 \\
\hline $\begin{array}{l}\text { Kanat Ç̧1k1ş } \\
\text { Yüksekliği }\end{array}$ & $\mathrm{b}_{2}$ & $\mathrm{~mm}$ & 61,8 & 60,0 \\
\hline
\end{tabular}

Çizelge 9 daki yeni K' değerleri ile yeniden çizilen geometriler tekrar Ansys'e yüklenerek HAD hesaplamaları tekrarlanmış ve çözüm yakınsadıktan sonra sonuçlar kaydedilmiştir.

Analiz sonucu çıkan değerler Çizelge $10 \mathrm{da}$ verilmiştir.

Çizelge 10. Yenilenen Church fanı HAD değerleri

\begin{tabular}{|c|c|c|c|}
\hline 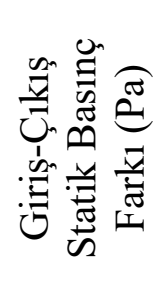 & 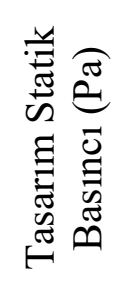 & 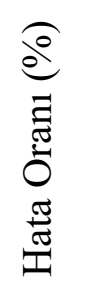 & 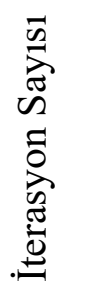 \\
\hline 12.861 & 13.435 & 4,27 & 1980 \\
\hline
\end{tabular}

K' katsayısının 0,57 seçilmesi ile birlikte HAD analizi sonucu \%4 lük bir hata oranıla tutturulmuştur. Yani bu yapıdaki bir geriye eğimli kanatlı santrifüj fan, tasarım koşullarında, $\mathrm{K}^{\prime}$ katsayısı 0,57 değerinde seçilerek oluşturacağı statik basınç, \%4,27 oranında bir hassasiyetle tasarlanabilmiştir.

\section{Sonuç ve Tartışma}

Austin Church (Church, 1947)'ün hesap yöntemi kullanılarak tasarlanan fanın HAD analizi sonunda $\mathrm{K}^{\prime}$ katsayısının değiştirilmesi ile kalibre edilen tasarımın nihai HAD analiz sonuçları çıkarılmıştır. Bu sonuçlardan en önemlisi olan fanın oluşturmasını istediğimiz basınç farkının HAD analiz sonucu Şekil 8 de verilmiştir

Şekil 8 de fanın çıkış kesitinde atmosfer basıncının sabit olduğu görülmektedir. Giriş kesitinde ise $88.464 \mathrm{~Pa}$ ile $88.461 \mathrm{~Pa}$ arasında değişen bir skalada basınç dağılımı gösterilmiştir.

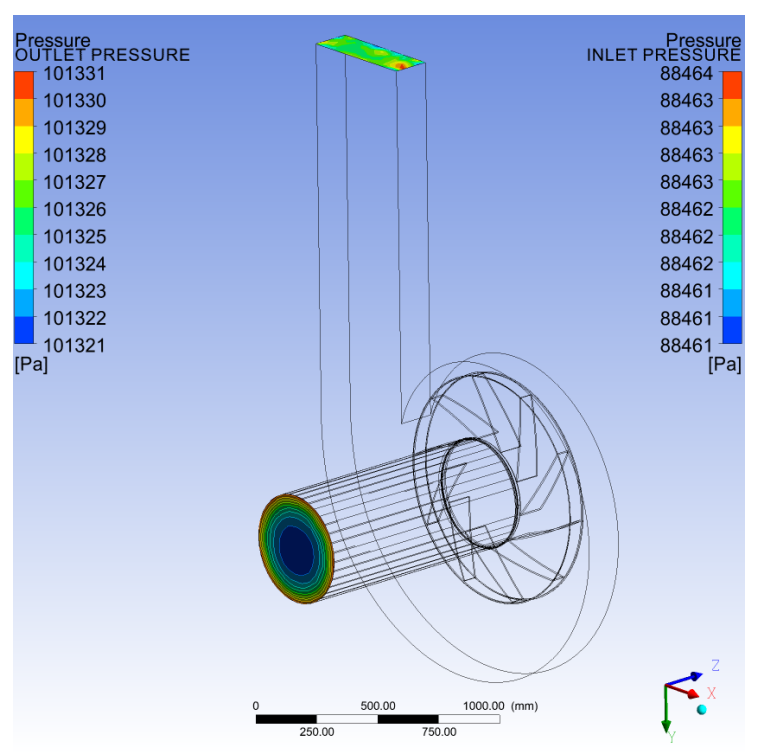

Şekil 8. Yenilenen Church fanının HAD statik basınç sonuçları 
Girişte ortalama $88.461 \mathrm{~Pa}$ lik bir ortalama statik basınç oluştuğu varsayılırsa çıkışla aradaki basınç farkı $12.864 \mathrm{~Pa}$ olarak aşağıdaki formülle hesaplanır;

$P_{\text {giriş }}-P_{c ̧ l k l s}=-P_{\text {fan }}$

Hatırlanacağı üzere fanın tasarım basınc1 13.435 Pa idi. Hata payı ise aşağıdaki eşitlikle hesaplanırsa

$$
\frac{P_{\text {Tasaraa }}-P_{\text {Fan }}}{P_{\text {Tasara }}} \times 100
$$

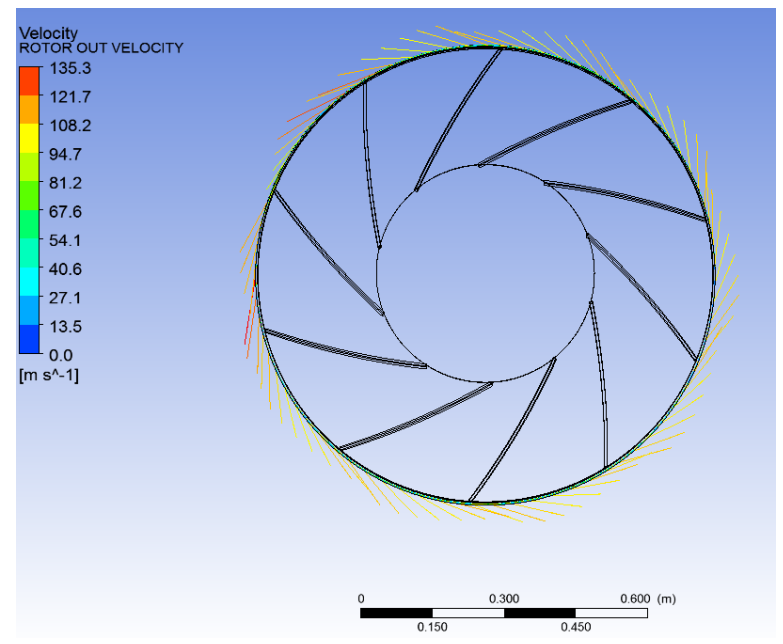

Şekil 9. Yenilenen Church fanının çark çıkış kesidi hız dağılımı

$\%$ 4,25 bulunur. HAD sonuçlarına göre fan girişindeki hava tüm giriş kesidi boyunca neredeyse eşit olarak $30,4 \mathrm{~m} / \mathrm{sn}$ bir hızla kanala girmektedir. $\mathrm{Bu}$ rakamı tasarım değerlerimizle karşılaştırmak istersek bu rakamın analitik hesaplamaların son iterasyonunda $31,60 \mathrm{~m} / \mathrm{sn}$ olduğunu görürüz. Buradaki hata payı ise $\% 3,95$ olarak hesaplanır.

Çark çıkışındaki hızlar incelenmek istenirse Şekil 9 karşımıza çıkmaktadır.

Burada 135,3 m/sn ile $0 \mathrm{~m} / \mathrm{sn}$ arasinda hizlar değişmektedir. $0 \mathrm{~m} / \mathrm{s}$ lik akışkan partikül hız değeri çark yüzeyi ile kanat yüzeyinin kesiştiği ara düzlem çizgisi üzerindeki nümerik olarak durgunluk noktasının bulunduğu bölgelerde hızın 0 olması olağandır. Bu duruma göre şekildeki skalanın üzerindeki hızın 0 olması mümkündür.

Yenilenen Church fanı geometrisi sonucu Şekil 9 da gösterilen çark çıkışındaki hız bileşke vektörlerinin CEL (CFX Expression Language) ile alan ortalaması alındığında $96,98 \mathrm{~m} / \mathrm{s}$ değeri nümerik çözümden bulunmuştur. $\mathrm{Bu}$ değer yine $\mathrm{K}^{\prime}$ katsayısının değişmesi ile yenilenen tasarıma göre analitik olarak çözdüğümüz değerler ile karşılaştırılmıştır. Karşılaştırma incelendiğinde analitik olarak bulmuş olduğumuz "Gerçek Mutlak Çıkış Hızı" $94,72 \mathrm{~m} / \mathrm{s}$ ile nümerik sonuç olan $96,98 \mathrm{~m} / \mathrm{s}$ değeri arasında \% 2,4 lük bir far çıkmaktadır. $\mathrm{Bu}$ fark kabul edilebilir olarak görülmektedir.

Çark yüzeyindeki hız ve basınç değerlerinden başka çark ile salyangoz arasındaki boşluğun ortalama çizgisi üzerindeki Şekil 10 da gösterilen S1- S30 noktalarındaki hiz ve basınç değerleri Şekil 11 ve Şekil 12 de gösterilmiştir. 


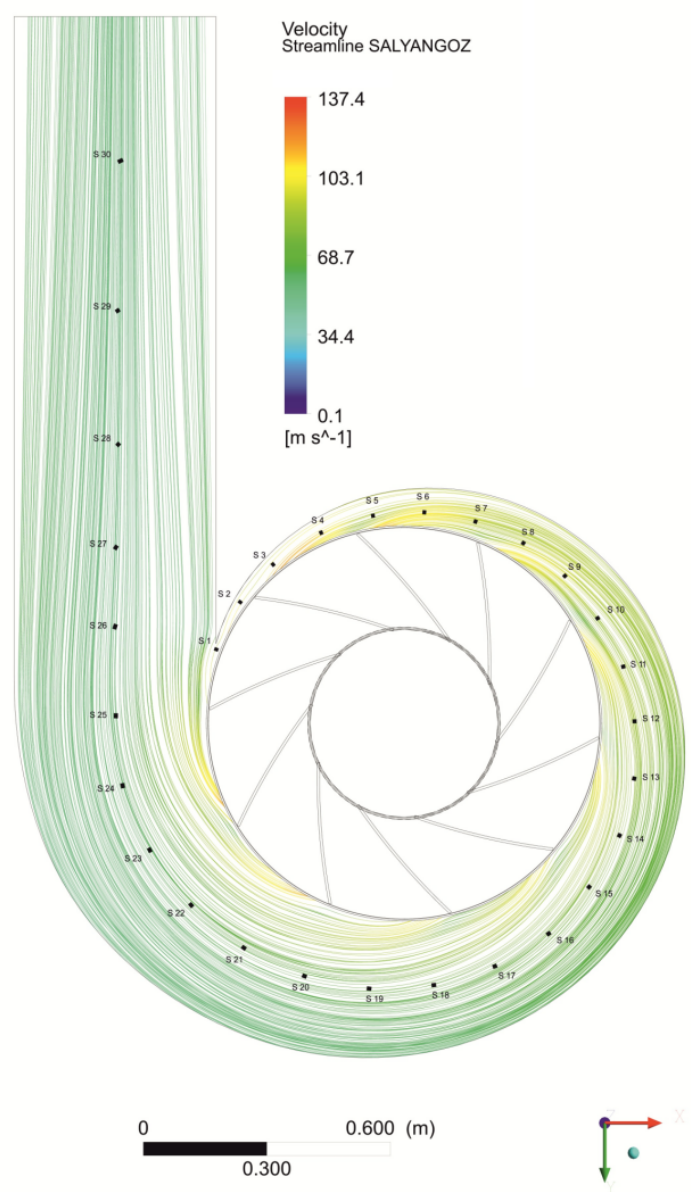

Şekil 10. Salyangoz düzlemi akış çizgileri ve noktalar1

Salyangoz boğazından başlayıp salyangoz çıkışına kadarki boşluğun orta çizgisi üzerinde hız ve basınç değerlerinin Bernoulli denkleminin tam uyarlanması görülmektedir.

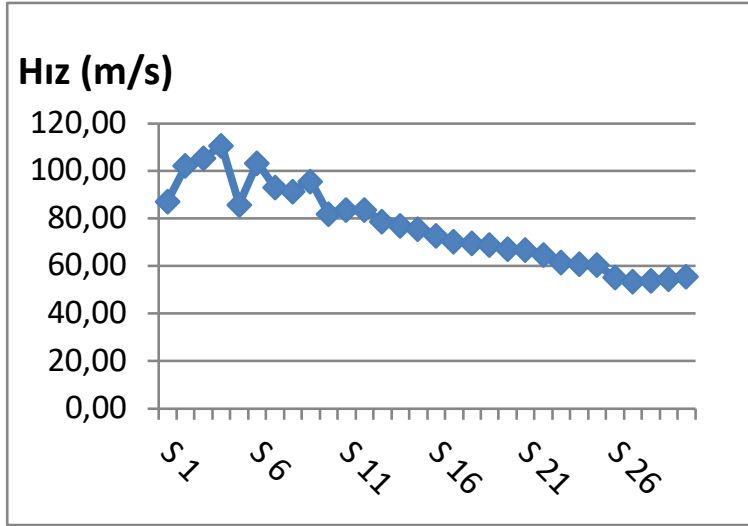

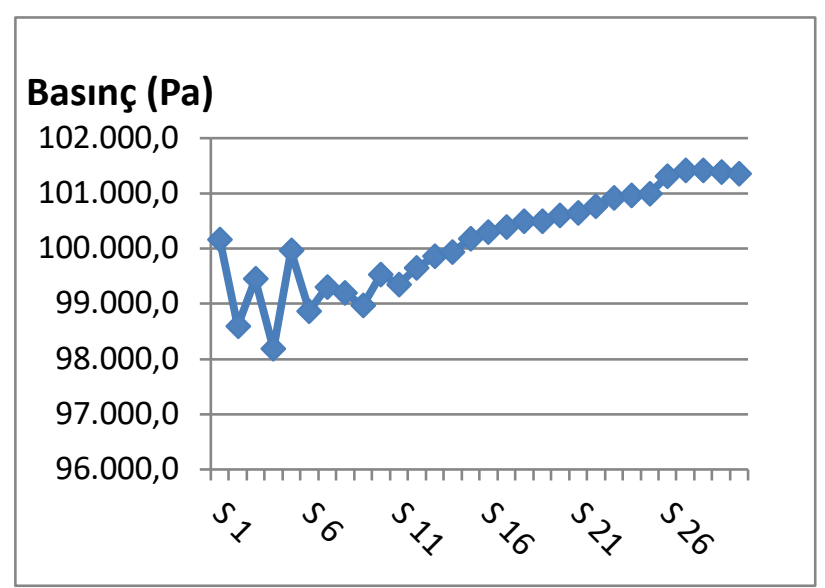

Şekil 12. Salyangoz noktaları basınç değerleri

Salyangoz boğaz bölgesinde akışkanın ağırlık kuvveti (body kuvveti) G vektörü ile aynı olmasından dolayı basınç ve hızlarda zigzaglar görülmektedir. S3 den itibaren Bernoulli denklemine uygunluğu görülmüştür.

Son olarak salyangoz çıkışını inceleyelim. Fanın çıkış kesitinin hız dağılımı Şekil 13 de 57,7 ile $0 \mathrm{~m} / \mathrm{sn}$ arasında değişmektedir. Çıkış kesidi dikdörtgen kesit olmasından dolayı kenarlarda ve nümerik çözümde belirtilen sınır şartlarında akışkan ile çeper arasında kaymazlık etkisinden dolayı hı 0 görülmektedir. Yenilenen Church fanının analitik çözümündeki salyangoz tasarımında hesaplanan ortalama hiz $\left(\mathrm{V}_{\text {ort }}\right) 60,68 \mathrm{~m} / \mathrm{sn}$ bulunmuştur. Aradaki fark \%4,91 olup bu değerin nümerik akışkanlar mekaniği çözümünün kabul kriteri olan $\% 7$ den küçük olduğu görülmektedir.

Çark çıkış hızının ve salyangoz çıkış hızının HAD yöntemi sonucu ve analitik çözüm

Şekil 11. Salyangoz noktaları hız değerleri 
sonuçlarının karşılaştırılması Çizelge 11 de verilmiştir.

Çizelge 11. HAD sonuçlarının analitik sonuçlarla karşılaştırılması

\begin{tabular}{|l|c|c|c|}
\hline & $\begin{array}{c}\text { HAD } \\
(\mathrm{m} / \mathrm{s})\end{array}$ & $\begin{array}{c}\text { Analitik } \\
(\mathrm{m} / \mathrm{s})\end{array}$ & $\begin{array}{c}\text { Fark } \\
(\%)\end{array}$ \\
\hline Çark çıkış hızı & 96,98 & 94,72 & 2,40 \\
\hline $\begin{array}{l}\text { Salyangoz çı1kş } \\
\text { hızı }\end{array}$ & 57,70 & 60,68 & 4,91 \\
\hline
\end{tabular}

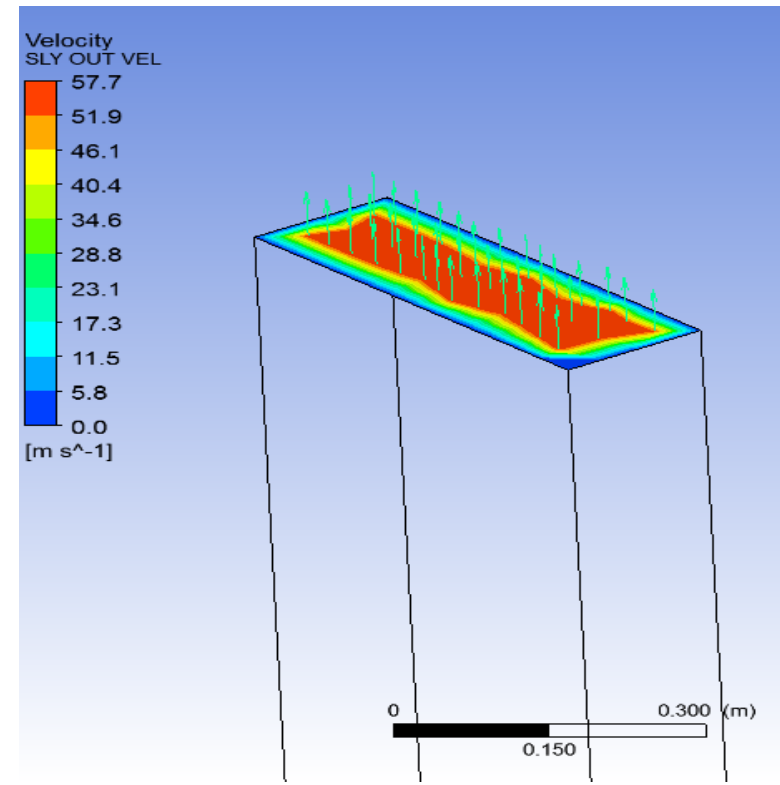

Şekil 13. Yenilenen Church fanının salyangoz gövdesi çıkış kesiti hız dağılımı

Araştırmamızda seçilen bir tasarım metodu ile sıfırdan bir fan tasarlanmış ve HAD yöntemi sonucuna göre güncellenmiştir. HAD yönteminin doğruluğunu ve hassasiyetini tespit edebilmek için ise önceden test edilmiş fan eğrilerine sahip olan CBC firmasının ürün gamından bir fan seçilerek HAD yöntemi ayarları ile çıkan sonuç bu eğrinin tasarım noktasındaki statik basınç ile karşılaştırılmıştır. Farklı ağ ayarları ve kaliteleri ile ağ yapısı oluşturulmuş geometri analiz edilmiş ve en uygun ağ ayarları tespit edilmiştir. Sonuçta çıkan statik basınç farkı $\mathrm{CBC}$ fan eğrisinin tasarım noktasındaki statik basınç ile karşılaştırılmış ve $\% 5$ lik bir hata payı ile sonuç tutturulmuştur. Daha sonra $\% 5$ hassasiyet ile kalibre edilen bu HAD ayarları ile Church yöntemi ile yeniden tasarlanan fan geometrisi analiz edilmiş ve ilk olarak \%11 civarında çıkan hata payı, K' katsayısının güncellenmesi ile $\% 4$ e düşürülmüştür. $\mathrm{Bu}$ sayede bu tip fanın bu tasarım koşullarında istenen performansı verebilmesi için kullanılması gereken ve çark içindeki sürtünme ve türbülans kayıplarının Church yöntemindeki karşıllı̆ 1 olan $\mathrm{K}^{\prime}$ katsayıs1 HAD yöntemi kullanılarak tespit edilmiştir. Church'e (Church, 1947) göre bu katsayı yalnızca deney sonuçları ile tespit edilebilirken gelişen HAD yöntemleri sayesinde deney düzeneğine gerek kalmadan hem zaman kaybinı hem de deney masraflarını ortadan kaldırarak \%4 hassasiyetle tespit edilebilmiştir.

Daha sonra fan girişinde itibaren HAD sonuçları analitik hesap sonuçları ile karşılaştırılmış ve yorumlanmıştır. Fan girişindeki emiş borusundaki akışkanın gelişmişlik düzeyi incelenmiş, tam gelişmişlik durumuna ulaşamamasının sebebinin fanın vakum etkisi olduğu sonucuna ulaşılmıştır. Çarka girdikten sonra merkezden dişarıya doğru çarktaki bir düzlem üzerindeki nokta ve bölümler teker teker incelenmiş ve sonuçları tartışılmıştır. Son olarak ise salyangoz üzerindeki noktaların hız ve basınç değerleri çıkarılarak çark çıkışı ile ilişkisi gösterilmiştir. Ayrıca tasarım aşamasında tespit edilen basınç ve hızlardan bazıları HAD sonuçları ile 
karşılaştırılmış ve bu değerlerin hepsinin akışkanlar mekaniği nümerik çözümlerinin kabul sınır değeri olan $\% 7$ nin altında çıktığ görülmüştür.

\section{Kaynakça}

Almeida, Fonseca, Bertoldi, 2002, Energyefficient motor systems in the industrial and in the services sectors in the European Union: characterisation,potentials, barriers and policies,SAcience Direct, Energy 28 (2003) 673-690

ANSYS Inc., 2009, Meshing Help Document.Reliese 12.1, page 102 .

ANSYS Inc., 2006, Innovative Turbulance Modeling: SSTModelin ANSYS CFX.

Balje O. E., 1981 Turbomachines, John Wiley \& Sons, 514, New York.

Bleier F. P.,1998, Fan Handbook. McGrawHill, 397p, Chicago.

Bruno E., 1972, Fans, Design and Operation of Centrifugal, Axial-Flow and Cross Flow Fans, Pergamon Press,611p, Oxford.

Bulgurcu H.(Ed.), 2015. Havalandırma Tesisatı (94-141), MMO İstanbul Şube 31. Dönem Havalandırma Tesisatı Kitap Komisyonu,.620s, İstanbul.

Church A. H., 1947, Centrifugal Pumps and Blowers. John Wiley \& Sons, 308 p, New York.

Çengel Y. A., Boles M. A., 1996, Mühendislik Yaklaşımıyla Termodinamik.
Çev. Taner Derbentli, McGraw-HillLiteratür, 867s, İstanbul.

Çengel Y. A.,Cimbala J. M., 2014, Fluid Mechanics Fundamentals and Applications, 3rd Addition. McGraw-Hill, 1006 p, New York.

Denton J. D., 1993, Loss Mechanisms in Turbo Machines., Journal of Turbomachinery, Transactions of the ASME, Volume 115, 40, England

IS 4894, 1987, Indian Standarts Specification for Centrifugal Fans, Reaffirmed in 1994. IS, India. Aktaran: Vibhakar N. N.,2012, Studies on Radial Tipped Centrifugal Fan. Veer Narmad South Gujarat Universiy, Faculty of Engineering Including Technology, Phd, Thesis,350p, Surat.

Kearton W. J., 1942,Influence of Number of Impeller Blades on the Pressure Generated in a Centrifugal Compressor and on its General Performance. Proceedings of Institute of Mechanical Engineers, pp. 481-568, 88p, England.

Kovatz A.., Desmur G., 1958. Pumps, Fans and Compressors, Blackie \& Son Ltd, 327p New York,

Krepper E., Willschütz H. G., and F. P. Weiss, 1999, Solution of a Mixed Convection Flow Benchmark Using Computational Fluid Dynamic Codes. Japan Society of Mechanical Engineers, 9 p, Tokyo.

Myles D. J., 1969, An Analysis of Impeller and Volute Losses in Centrifugal Fans, 
National Engineering Laboratory, 253-277p, Glasgow.

Osborne William C., 1977, Fans Pergamon Press.,228p, New York. Aktaran: Vibhakar N. N., 2012, Studies on Radial Tipped Centrifugal Fan. Veer Narmad South Gujarat Universiy, Faculty of Engineering Including Technology, Phd, Thesis,350p, Surat

Roache P. J., 1997, Quantification of Uncertainty in Computational Fluid Dynamics. Annual Review of Fluid Mechanics, Volume 29, pp. 123-160, 36p, New Mexico.

Siwek T., Gorski J., Fortuna S.,2014, Numerical and Experimental Study of Centrifugal Fan Flow Structures and Their Relationship with Machine Efficiency. AGH University of Science and Technology, Pol. J. Environ. Stud. Vol. 23 N. 6 (2014), 23592364, Poland.

Stepanoff A. J., Haltmeier A., 1957, Radial und Axialpumpen. Springer,401p, Berlin

Stodola A. 1945, Steam and Gas Turbines. Peter Smith Publications, 1356p New York, Türkiye İstatistik Kurumu (TÜİK), 2016. Net Elektrik Tüketiminin Sektörlere Göre
Dağılımı. Erişim Tarihi: 05.07.2019. http://www.tuik.gov.tr/

Tsuei H., Oliphant K., Japikse D., 1999, The Validation of Rapid CFD Modeling for Turbomachinery. Institution of Mechanical Engineers, England, 22p, England.

Vibhakar N. N.,2012, Studies on Radial Tipped Centrifugal Fan. Veer Narmad South Gujarat Universiy, Faculty of Engineering Including Technology, Phd, Thesis,350p, Surat.

Waide P., Brunner, C.U., 2011. Energy Efficiency Policy Opportunities fir Electric Motor-Driven Systems. Internationale energy agency. Aktaran: Esen,2015. Türkiye ve Dünyada Elektrik Mototrları Enerji Tüketimi ve İlgili Teknik Mevzuat. Türk Standartları Enstitüsü Elektroteknik Laboratuarları Gebze Müdürlügüu, Kocaeli, (3), 6s.

Whitfield A., Baines N. C., 1990, Design of Radial Turbomachines. Longman Scientific \& Technical Publications, $414 p$, England. 